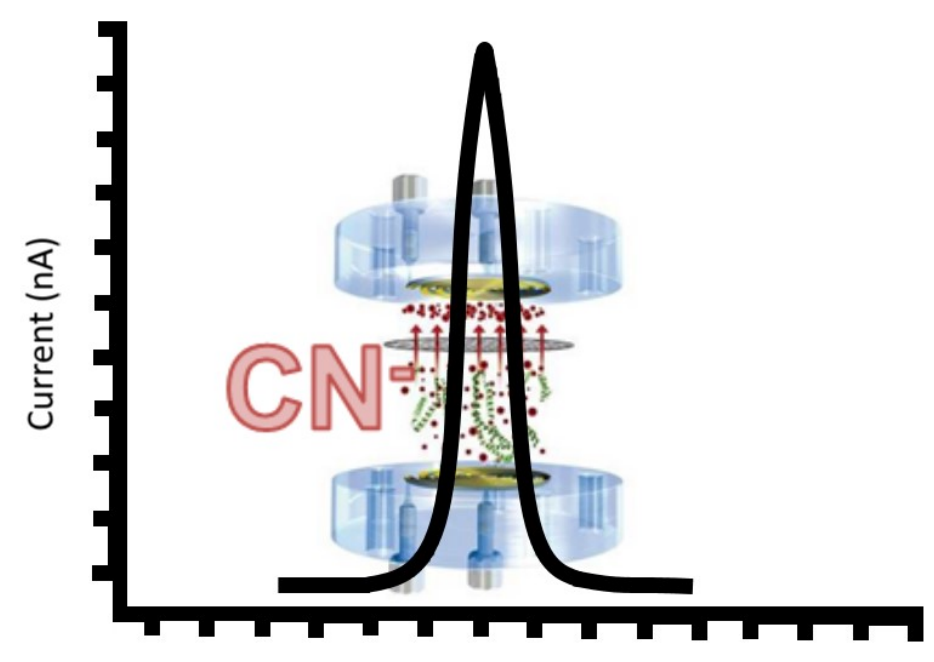

Time (minutes)

Graphical Abstract: Cyanide determination using ion chromatography with amperometric detection by flow analysis using gas-diffusion

\title{
ESTRATÉGIAS PARA DETERMINAÇÃO DE CIANETO EM ÁGUAS POR ANÁLISE EM FLUXO E CROMATOGRAFIA DE ÍONS \\ Mikhael Kimitoshi Abe ${ }^{1,2^{*}}$, Jorge Cesar Masini ${ }^{1 *}$, Eduardo Simões ${ }^{2^{*}}$ \\ 1 -Instituto de Química, Universidade de São Paulo (USP), São Paulo, SP \\ 2 - Laboratório de Aplicações, Metrohm Brasil, São Paulo, SP \\ mikhael.abe@metrohm.com.br
}

\begin{abstract}
Resumo: $\mathrm{O}$ íon cianeto $\left(\mathrm{CN}^{-}\right)$é um importante parâmetro de controle ambiental e de saúde devido ao seu potencial tóxico. Neste trabalho foram estudadas abordagens de análise em fluxo acoplada a cromatografia de íons com detecção amperométrica para a determinação do cianeto. Foram estudadas as interferências de outros ânions comumente presentes em amostras de interesse ambiental e de saúde na quantificação de $70 \mu \mathrm{g} \mathrm{L}^{-1} \mathrm{de} \mathrm{CN}^{-1} \mathrm{em}$ matriz aquosa. Através da adaptação de um sistema de diálise convertido em sistema de difusão gasosa foi obtida uma recuperação média de $98 \pm 1 \%$ de cianeto. Os limites de detecção e quantificação foram estimados em $6,7 \mu \mathrm{g} \mathrm{L}^{-1}$ e $10,0 \mu \mathrm{g} \mathrm{L}{ }^{-1}$, respectivamente. Os resultados demonstraram que o sistema em fluxo acoplado à separação cromatográfica com detecção amperométrica confere boa seletividade para determinação de cianeto.
\end{abstract}

Palavras-chave: cianeto; análise em fluxo; cromatografia de ions; difusão gasosa; análises de águas

\section{Strategies for cyanide determination in waters by flow analysis and ion chromatography}

Abstract: Cyanide $\left(\mathrm{CN}^{-}\right)$is a parameter of interest for environmental and health controls due to its toxic potential. In this work, flow analysis approaches coupled with ion chromatography and amperometric detection were studied for cyanide determination. The effect of interfering anions commonly present in environmental samples were evaluated in the quantification of $70 \mu \mathrm{g} \mathrm{L}^{-1} \mathrm{CN}^{-}$in aqueous matrix. Using a dialysis system converted into a gas-diffusion system, a mean recovery of $98 \pm 1 \%$ was achieved. The limits of detection and quantification were estimated as $6.7 \mu \mathrm{g} \mathrm{L}^{-1}$ and $10.0 \mu \mathrm{g} \mathrm{L}^{-1}$, respectively. The results demonstrated that the flow-system coupled to chromatographic separation and amperometric detection provided good selectivity for cyanide determination. 
Keywords: cyanide; flow analysis; ion chromatography; gas-diffusion; water analysis

\section{Introdução}

O ânion monovalente de cianeto consiste em um átomo de carbono ligado a um átomo de nitrogênio através de uma tripla ligação. Sua ocorrência pode ser natural ou resultante de processos industriais. Sob a forma do ácido cianídrico, $\mathrm{HCN}$, pode ser encontrado na atmosfera terrestre, oriundo de processos vulcânicos e de queima de biomassa. Biologicamente, é encontrado em pelo menos duas mil espécies de plantas na forma de glicosídeos com funções imunológicas. ${ }^{1-4}$

O cianeto é conhecidamente tóxico, sendo letal mesmo quando a exposição ocorre a baixas concentrações. Através de ligação com a enzima citocromo oxidase mitocondrial, a respiração celular é inibida provocando morte por sufocamento. Os efeitos clínicos são observados em menos de um minuto após a inalação e em alguns minutos no caso de ingestão. ${ }^{5-7}$

No Brasil, a portaria 2914 do Ministério da Saúde define valores máximos permitidos de $0,07 \mathrm{mg} \mathrm{L}^{-}$ ${ }^{1}\left(70 \mu \mathrm{g} \mathrm{L}^{-1}\right)$ de cianeto para potabilidade de águas. ${ }^{8}$ Com relação aos efluentes, a resolução 430 (357) do Conselho Nacional do Meio Ambiente, órgão vinculado ao Ministério do Meio Ambiente, define como valores padrão máximos de $1 \mathrm{mg} \mathrm{L}^{-1}\left(1000 \mu \mathrm{g} \mathrm{L}^{-1}\right)$ de cianeto total e de $0,2 \mathrm{mg} \mathrm{L}^{-1}$ $\left(200 \mu \mathrm{g} \mathrm{L}^{-1}\right)$ de cianeto livre (destilável por ácidos fracos) para o lançamento de efluentes. ${ }^{9}$

Devido a sua alta toxicidade em baixas concentrações, diversas estratégias analíticas têm sido desenvolvidas para quantificar as concentrações destas espécies em águas e efluentes. Métodos oficiais incluem titulação, espectrometria, potenciometria, análise por injeção em fluxo com detecção amperométrica, ${ }^{2}$ sendo os métodos mais comuns os espectrofotométricos. Trabalhos recentes têm explorado o uso de sensores baseados em nanopartículas de ouro (AuNP's) para a detecção de ânions em águas contaminadas aproveitando as promissoras seletividade e sensibilidade destes materiais. ${ }^{6,10}$

Em um contexto em que metodologias de estado-da-arte ainda carecem de mão-de-obra especializada e instrumentações estabelecidas, o desenvolvimento de uma estratégia simples e robusta de preparo de amostra em fluxo, associada a uma técnica analítica seletiva como a cromatografia iônica com detecção amperométrica, pode ser de grande interesse às agências reguladoras ambientais, bem como aos prestadores de serviços de análises químicas.

O objetivo deste trabalho foi desenvolver e validar metodologia automatizada para a determinação de cianeto usando análise em fluxo combinada com cromatografia de íons e detecção amperométrica.

\section{Experimental}

\section{Instrumentação}

Para as avaliações das estratégias em fluxo foi utilizado um autoamostrador modelo 858 Professional Sample Processor (Metrohm). Neste amostrador foi posicionada uma célula de difusão gasosa com membrana hidrofóbica de PTFE. Para a separação de cianeto de outros interferentes iônicos foi usado um cromatógrafo modelo 930 Compact IC Flex (Metrohm), coluna de troca aniônica Metrosep A Supp 10 (Metrohm) de $100 \mathrm{~mm}$ de comprimento e $2 \mathrm{~mm}$ de diâmetro interno. 
A fase móvel utilizada foi composta de uma solução de $\mathrm{NaOH} 0,1 \mathrm{~mol} \mathrm{~L}^{-1}$ e EDTA $0,007 \mathrm{mmol} \mathrm{L}^{-1}$ Para a quantificação de cianeto foi usado um detector amperométrico modelo IC Amperometric Detector (Metrohm). Neste detector foi usada uma célula eletroquímica feita em PEEK (poli éter éter cetona) de geometria do tipo wall-jet, composta por um eletrodo de referência sólido $\mathrm{Pd}|\mathrm{PdO}| \mathrm{OH}^{-}\left(0,1 \mathrm{~mol} \mathrm{~L}^{-1}\right)\left(\mathrm{E}=-0,038 \mathrm{~V}\right.$ vs. $\left.\mathrm{Ag}|\mathrm{AgCl}| \mathrm{KCl}\left(3 \mathrm{~mol} \mathrm{~L}^{-1}\right)\right)$, um eletrodo auxiliar de aço inox e um eletrodo de trabalho de prata $(\mathrm{Ag})$ com $3 \mathrm{~mm}$ de diâmetro potencial fixo de $0,0 \mathrm{~V}$. Equipamentos e resultados analíticos foram controlados e processados através do software de cromatografia MagIC Net $3.3^{\circledR}$ (Metrohm) instalado em um microcomputador (Dell).

\section{Estudos de interferência aniônica}

Para avaliação de potenciais interferentes aniônicos foram estudados ânions comumente presentes em amostras aquosas de interesse ambiental e de saúde pública. Foram estudados seus efeitos na determinação de cianeto e em três níveis de concentração (em mol L $\left.{ }^{-1}\right)$ denominados $\mathrm{C} 1, \mathrm{C} 2$ e C3. Para cada nível, analisado em triplicata, a concentração do interferente presente foi 10, 100 e 1000 vezes maior que a concentração máxima (em mol L $\left.{ }^{-1}\right)$ permitida do íon cianeto em água potável, segundo os parâmetros de potabilidade de águas no Brasil que é de $70 \mu \mathrm{g} \mathrm{L}^{-1}$, ou 2,7 × $10^{-6} \mathrm{~mol} \mathrm{~L}^{-}$ 18

\section{Resultados e Discussão}

A Figura 1 mostra esquematicamente uma configuração onde um volume aproximado de $3 \mathrm{~mL}$ de amostra foi bombeado para a alça de $200 \mu \mathrm{L}$ (injetor 1 ) em vazão de $0,3 \mathrm{~mL} \mathrm{~min}^{-1}$. Após 1 minuto, o injetor 1 mudou para posição de injeção, injetando o volume de amostra no percurso analítico, no qual é transportado por um fluxo de água a $0,3 \mathrm{~mL} \mathrm{~min}^{-1}$ até um ponto de confluência onde se mistura com uma solução de ácido sulfúrico $1 \mathrm{~mol} / \mathrm{L}(\mathrm{pH}<1)$ bombeada com uma vazão de $0,3 \mathrm{~mL}$ $\min ^{-1}$. A mistura de amostra e solução ácida foi passada por um capilar em espiral para homogeneização e chegou até a célula de difusão gasosa equipada com uma membrana hidrofóbica de PTFE. Na célula, o gás cianídrico $(\mathrm{HCN})$ difundiu até uma solução aceptora alcalina $(\mathrm{pH}=12,7)$ de composição idêntica à fase móvel. Esta solução aceptora foi então bombeada em vazão de 0,3 $\mathrm{mL} \mathrm{m^{-1 }}$ por intervalos variados de tempo até a válvula de injeção do cromatógrafo. Foram usados capilares de $0,5 \mathrm{~mm}$ de diâmetro interno e mangueiras de $0,76 \mathrm{~mm}$ de diâmetro interno nas bombas peristálticas.

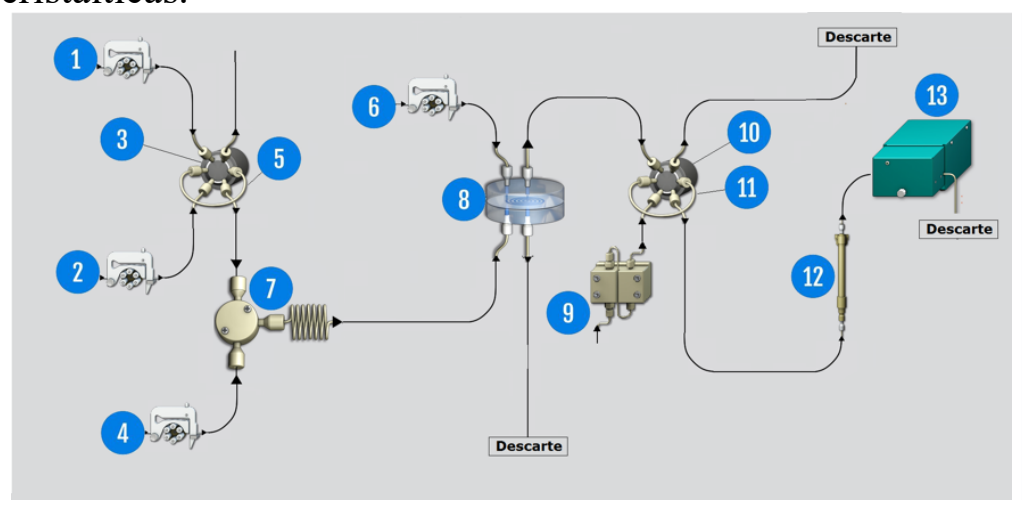

\begin{tabular}{|r|l|}
\hline$\#$ & Legenda \\
\hline 1 & Bomba Peristáltica - Amostra \\
\hline 2 & Bomba Peristáltica - Água Ultrapura \\
\hline 3 & Injetor 1 \\
\hline 4 & Bomba Peristáltica - Solução Ácida \\
\hline 5 & Alça de Amostragem 1 - 200 $\mu \mathrm{L}$ \\
\hline 6 & Bomba Peristáltica - Solução Aceptora Alcalina \\
\hline 7 & Misturador \\
\hline 8 & Célula de Difusão \\
\hline 9 & Bomba de Eluente \\
\hline 10 & Injetor 2 \\
\hline 11 & Alça de Amostragem 2 - $20 \mu \mathrm{L}$ \\
\hline 12 & Coluna Cromatográfica \\
\hline 13 & Detector Amperométrico \\
\hline
\end{tabular}

Figura 1: Esquema de acidificação, difusão gasosa e cromatografia em fluxo 
Nas condições descritas na Figura 1 foi realizado um teste de otimização para obtenção do maior sinal analítico do íon cianeto no detector amperométrico. Com as bombas peristálticas funcionando continuamente, variou-se os tempos entre a injeção de amostra bruta no injetor 1 e a injeção de solução aceptora no injetor 2. As áreas ( $\mathrm{nA} \times \mathrm{min}$ ) do pico de cianeto foram monitoradas e chegouse ao tempo ótimo de 65 segundos conforme mostrado na Figura 2.

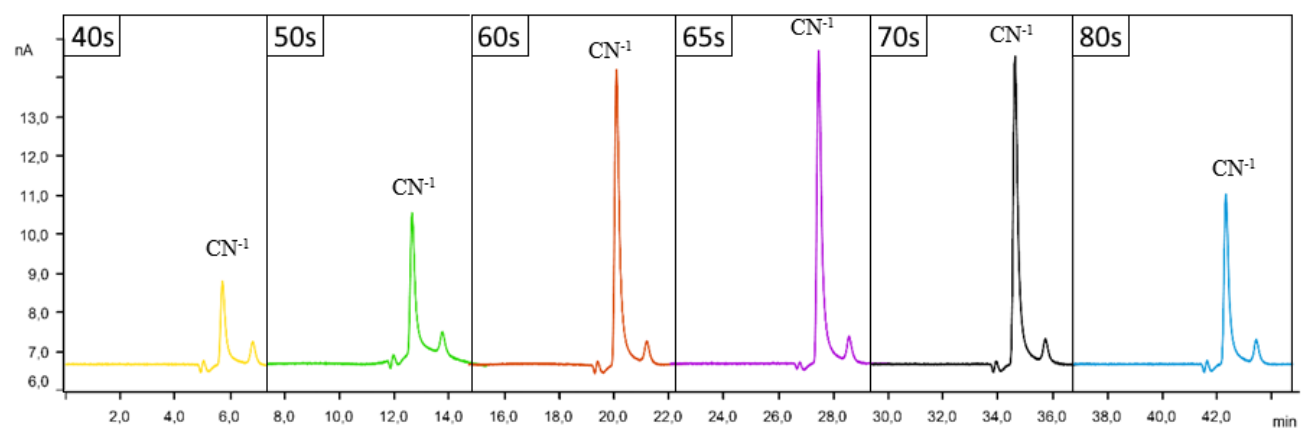

Figura 2: Cromatogramas de padrão $70 \mu \mathrm{g} \mathrm{L}^{-1}$ de $\mathrm{CN}^{-}$obtidos variando-se o tempo decorrido entre a injeção na válvula 1 e a injeção na válvula 2 do cromatógrafo

Após a otimização, foi construída uma curva analítica de cianeto nas concentrações de 10 a $130 \mu \mathrm{g}$ $\mathrm{L}^{-1}$ cuja equação da reta foi dada por: Área do Pico $\left.(\mathrm{nA} \times \mathrm{min})=0,0341 \times \mathrm{CN}^{-}\right]\left(\mu \mathrm{g} \mathrm{L}^{-1}\right)+0,0004$. Obteve-se um coeficiente de correlação linear de 0,9996 (Figura 3). Os limites de detecção e quantificação baseados nos parâmetros de calibração com intervalo de confiança de $95 \%$ foram de $6,7 \mu \mathrm{g} \mathrm{L}-1$ e $10,0 \mu \mathrm{g} \mathrm{L}^{-1}$, respectivamente.

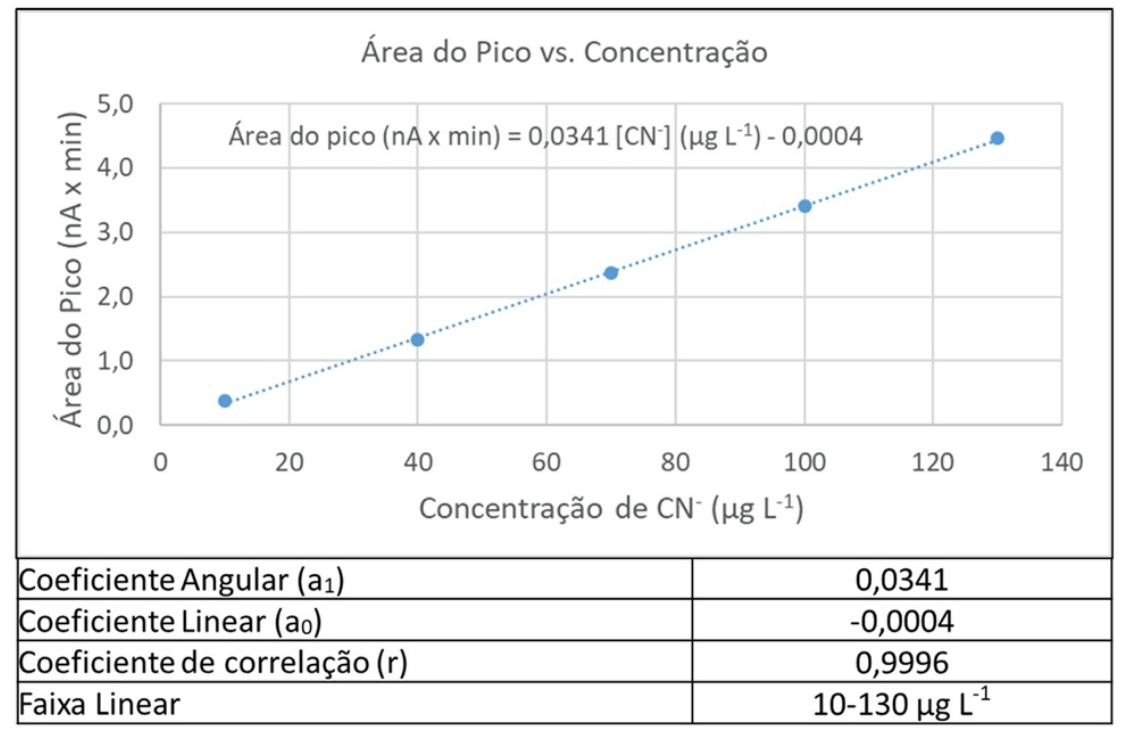

Figura 3: Curva analítica de cianeto

Em seguida foram determinadas as taxas de recuperação de cianeto nas amostras-teste em presença da interferência aniônica (Tabela 1). A recuperação média de cianeto foi de 98,5\% para o nível C1, 98,0\% para o nível C2 e 96,4\% no nível C3 de presença dos interferentes aniônicos. 
Tabela 1: Concentrações de interferentes e taxas de recuperação obtidas para uma solução $70 \mu \mathrm{g}$ $\mathrm{L}^{-1}$ de cianeto no sistema de difusão gasosa em fluxo seguido de cromatografia iônica

\begin{tabular}{|c|c|c|c|c|c|c|c|c|c|}
\hline \multirow[b]{2}{*}{$(n=3)$} & \multicolumn{3}{|c|}{ Nível C1 $\left(2,5 \times 10^{-5} \mathrm{~mol} \mathrm{~L}^{-1}\right)$} & \multicolumn{3}{|c|}{ Nível C2 $\left(2,5 \times 10^{-4} \mathrm{~mol} \mathrm{~L}^{-1}\right)$} & \multicolumn{3}{|c|}{ Nível C3 $\left(2,5 \times 10^{-3} \mathrm{~mol} \mathrm{~L}^{-1}\right)$} \\
\hline & $\begin{array}{l}{\left[\mathrm{CN}^{-}\right]} \\
\mu \mathrm{g} \mathrm{L}^{-1}\end{array}$ & $\begin{array}{c}\text { Rec } \\
\%\end{array}$ & $\begin{array}{c}\text { DR. } \\
\%\end{array}$ & $\begin{array}{l}{\left[\mathrm{CN}^{-}\right]} \\
\mu \mathrm{g} \mathrm{L}^{-1}\end{array}$ & $\begin{array}{c}\text { Rec } \\
\%\end{array}$ & $\begin{array}{c}\text { DR. } \\
\%\end{array}$ & $\begin{array}{l}{\left[\mathrm{CN}^{-}\right]} \\
\mu \mathrm{g} \mathrm{L}^{-1}\end{array}$ & $\begin{array}{c}\text { Rec } \\
\%\end{array}$ & $\begin{array}{c}\text { DR. } \\
\%\end{array}$ \\
\hline Fluoreto & $70,5 \pm 1,7$ & 100,7 & 0,7 & $66,9 \pm 2,2$ & 95,6 & $-4,4$ & $69,7 \pm 0,6$ & 99,6 & $-0,4$ \\
\hline Nitrato & $73 \pm 6,1$ & 104,3 & 4,3 & $68,2 \pm 0,5$ & 97,4 & $-2,6$ & $68,2 \pm 0,7$ & 97,4 & $-2,6$ \\
\hline Nitrito & $70,3 \pm 0,5$ & 100,4 & 0,4 & $67,4 \pm 1$ & 96,3 & $-3,7$ & $68,6 \pm 0,1$ & 97,9 & $-2,1$ \\
\hline Bromato & $66,6 \pm 0,2$ & 95,1 & $-4,9$ & $67,7 \pm 0,7$ & 96,8 & $-3,2$ & $65,2 \pm 2,5$ & 93,1 & $-6,9$ \\
\hline Clorito & $66,7 \pm 0,3$ & 95,3 & $-4,7$ & $67 \pm 1$ & 95,7 & $-4,3$ & $55,4 \pm 2,7$ & 79,2 & $-20,8$ \\
\hline Cloreto & $66,9 \pm 0,7$ & 95,6 & $-4,4$ & $67,7 \pm 0,2$ & 96,7 & $-3,3$ & $65,2 \pm 1,5$ & 93,1 & $-6,9$ \\
\hline Sulfato & $66,8 \pm 0,6$ & 95,4 & $-4,6$ & $67,1 \pm 0,5$ & 95,8 & $-99,2$ & $67,1 \pm 0,8$ & 95,9 & $-4,1$ \\
\hline Sulfeto & $70,5 \pm 1,0$ & 100,6 & 0,6 & $70,4 \pm 0,6$ & 100,6 & 0,6 & $73,5 \pm 0,4$ & 104,9 & 4,9 \\
\hline Brometo & $72,5 \pm 1,7$ & 103,6 & 3,6 & $74,2 \pm 0,8$ & 106,0 & 6,1 & $69,3 \pm 3,1$ & 98,9 & $-1,1$ \\
\hline Clorato & $67,9 \pm 3,2$ & 97,0 & $-3,0$ & $65,3 \pm 0,4$ & 93,3 & $-6,7$ & $66 \pm 3,0$ & 94,3 & $-5,7$ \\
\hline Tiossulfato & $65,5 \pm 3,7$ & 93,6 & $-6,4$ & $70,4 \pm 1,1$ & 100,5 & 0,5 & $71,1 \pm 1,2$ & 101,6 & 1,6 \\
\hline Fosfato & $70,3 \pm 0,6$ & 100,4 & 0,4 & $71 \pm 0,8$ & 101,4 & 1,4 & $70,5 \pm 0,2$ & 100,7 & 0,7 \\
\hline Média & $69 \pm 1,7$ & 98,5 & $-1,5$ & $68,6 \pm 0,8$ & 98,0 & $-2,0$ & $67,5 \pm 1,4$ & 96,4 & $-3,6$ \\
\hline
\end{tabular}

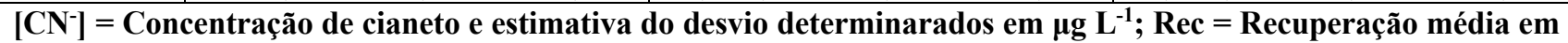
$\% ; \mathrm{DR}=$ Desvio relativo médio em \%

\section{Conclusões}

Os resultados do estudo demonstraram que a abordagem em fluxo proposta para a determinação de cianeto é potencialmente viável na presença de interferentes aniônicos. O acoplamento da difusão gasosa a um sistema cromatográfico com detecção amperométrica conferiu seletividade ao método frente à diversos níveis de concentração dos ânions comumente encontrados em amostras ambientais. Estas observações tornam a abordagem promissora para objetivos de estudo e monitoramento de cianeto em ambientes aquáticos.

\section{Agradecimentos}

Agradecemos ao Laboratório de Química Analítica Ambiental do IQ/USP e a Metrohm Brasil pela infraestrutura e recursos disponibilizados para a realização deste estudo.

\section{Referências}

1. Gavrilov, A. V.; Druzhinin, A. A.; Zakharov, K. I.; Ishutin, V. A.; Nemkov, S. A.; Pushkin, I. A.; J. Anal. Chem. 2005, 60, 1029-1034

2. $\quad$ Ma, J.; Dasgupta, P. K.; Anal. Chim. Acta 2010, 673, 117-125

3. Osbourn, A. E.; Plant Cell 1996, 8, 1821-1831

4. Jackson, R.; Logue, B. A.; Anal. Chim. Acta 2017, 960, 18-39

5. Zacharis, C. K.; Tzanavaras, P. D.; Voulgaropoulos, A. N.; Karlberg, B.; Talanta 2009, 77, 1620-1626

6. Kim, M. H.; Kim, S.; Jang, H. H.; Yi, S.; Seo, S. H.; Han, M. S.; Tetrahedron Lett. 2010, 51, 4712-4716

7. Hamel, J.; Crit. Care Nurse 2011, 31, 72-82

8. Ministério da Saúde; Portaria de Consolidação n ${ }^{\circ} 5$ de 28 de setembro de 2017. Consolidação das normas sobre as ações e os serviços de saúde do Sistema Único de Saúde. Diário Of. 2017

9. Ministério do Meio Ambiente - Conselho Nacional do Meio Ambiente; RESOLUÇÃO 430, DE 13 DE MAIO DE 2011. Diário Of. 2011

10. Fang, C.; Dharmarajan, R.; Megharaj, M.; Naidu, R.; Trends Anal. Chem. 2017, 86, 143-154 